\title{
EL DELITO DE HOMICIDIO
}

\section{Ramón Cortés Vaca Guzmán}

Sub Decano de la I. Corte Superior del Distrito de Tarija. Bolivia

I. DEFINICION. CARMIGNANI, es uno de los primeros que usa la definición "violenta hominis injusta patrata" (La muerte de un hombre ocasionada injusta y violentamente por otro hombre), él influye en la conceptualización usada por el gran jurista de Pisa GIUSEPPE CARRARA, en el entendido de que con el agregado de "injusta" quedaban excluidos aquellos cometidos con causas de justificación como la legítima defensa, y otros.

Luego, otros tratadistas, como es recogido por el argentino MARIO M. MALLO, quienes estiman que no resulta "necesario que la acción sea injusta, violenta, dolosa, culposa, etc., pues de no serlo no estaría incluido el homicidio en la parte especial de la codificación penal, y que trata de delitos que presuponen de la culpa en el autor". Consiguientemente, la fórmula .. muerte de una persona por otra", no desconoce esa verdad, pero señala que el tipo o figura del homicidio consiste en la muerte de un hombre por otro, con prescindencia de la justicia o injusticia del hecho.

II. BIEN PROTEGIDO. La represión del homicidio en su forma Simple, calificada, agravada, o atenuada protege la vida humana. Y ella, no sólo es un "bien jurídico" como creación del derecho; es, más bien, en un sentido fundamental, la razón de ser de todos los derechos; la vida como valor precede al derecho, el cual no la crea ni reconoce, sólo regula su disfrute y trata de protegerla, aunque la vida sea así un "objeto de protección jurídica" y por ello sea denominado en el lenguaje técnico "un bien jurídico"; no es, repetimos, una creación que se origina en el derecho, en todo caso, el derecho es una creación de la vida social del hombre.

Entonces, tenemos que el derecho penal cumple una función eminentemente sancionatoria, esto es, castiga el daño ocasionado pero, por su finalidad, no sólo es sancionatorio, sino también preventivo, por cuanto busca evitar la futura comisión de nuevos hechos punibles. En el cumplimiento de estos fines, el derecho penal se sirve de medios muy especiales: uno psicológico, o sea la intimidación, y otro, la pena pública, que es el medio utilizado preferentemente por el derecho que estudiamos, para combatir el delito y proteger la vida, así como las condiciones más importantes de las relaciones sociales.

En realidad, es más importante prevenir el delito mediante la amenaza ante el peligro abstracto, que ante el peligro concreto, pues el derecho penal sólo tiene explicación en cuanto quiere motivar a los hombres para que respeten la vida y la convivencia. La sanción al daño ejecutado nada repara, y por sí no tiene objeto. El derecho penal tiene su razón de ser en cuanto sirve hacia el futuro, como prevención del delito, y para que se respete la vida existente. Así cumple una función social, y no la meramente individual de ser medio colectivo de venganza del daño privado. Su 
verdadero papel histórico es el de cumplir la función social de proteger las condiciones de la existencia del hombre como ser social, respetando la condición humana.

III. LOS TIPOS PENALES. Entendemos por tipo la abstracción, realizada por el legislador, que reúne en un concepto los elementos esenciales de un hecho delictivo determinado, y por tipicidad la correspondencia entre aquel hecho ocurrido en la realidad y el descrito en el tipo, esto es, la conducta del hombre subsumida en el tipo legal.

Con este presupuesto conceptual, en la lectura del artículo 251 de la codificación penal boliviana, podemos apreciar que el homicidio simple, según la clasificación y especies de tipos aceptados por la doctrina, es uno (tipo) denominado general o básico, pues representa la figura simple del homicidio. De él, consecuentemente, se derivan los tipos especiales, esto es, aquellos que presentan modalidades diversas del tipo general, como ser el homicidio calificado, cualificado; agravado o asesinato, como se le denomina en Bolivia; Parricidio; Homicidio en Emoción Violenta; Homicidio en Prácticas Deportivas; Homicidio - Suicidio; Homicidio Piadoso; el Infanticidio; Homicidio en Riña a Consecuencia de una Agresión; el Homicidio Culposo, y por último, el Homicidio en Accidente de Tránsito.

En cuanto a la comunicabilidad, esto es, la permisión de todo aquello que admite la posibilidad de hacer partícipe a otro; la ley penal boliviana, resuelve el problema con la prescripción del Art. 24 del C.P. "(INCOMUNICABILIDAD). Las relaciones, cualidades y circunstancias Personales que aumenten o disminuyan la responsabilidad NO SE COMUNICAN LOS PARTICIPES."

Por el tenor del artículo citado, se entiende que éste extiende la incomunicabilidad a las circunstancias agravantes. Así en un parricidio, por ejemplo, constituye agravante para el parricida (Art. 38; b: vínculos de parentesco), pero quien ayuda a matarle, lo hace a un tercero, por tanto, el parricidio no puede comunicarse al partícipe, que mata a un extraño.

IV. ESPECIES. EI homicidio puede ir acompañado de circunstancias que aumenten o disminuyan su criminalidad. Y ellas, tienen distinta naturaleza, son las llamadas circunstancias agravantes (Calificantes, cualificantes) $\circ$ atenuantes. Consiguientemente, el homicidio puede dividirse en: a) Homicidio simple, y es aquél que no presenta circunstancias que agraven o atenúen su criminalidad. b) Homicidio agravado o calificado por sus circunstancias, y c) Homicidio atenuado por ellas (Circunstancias). Esta es una división universalmente aceptada. Lo que en alguna medida varían son las circunstancias a las que las distintas legislaciones les reconocen capacidad para agravar 0 atenuar la criminalidad del homicidio.

V.HOMICIDIO SIMPLE. Incurre en homicidio simple el que mata a otro. Así, el Art. 251 del Código Penal boliviano lo norma: "El que matare a otro, será sancionado con privación de libertad de uno a diez años". Es el homicidio voluntario, denominado meurtre por la codificación criminal francesa (Art. 295), o el homicidio doloso llamado totschlag por el Código Penal alemán (Art. 212). En el Código Penal chileno es formulado, por exclusión, de los tipos de Parricidio (Art. 390) y Homicidio Calificado Art. 391, en la circunstancia Quinta, inciso segundo, que norma in fine: “... en cualquier otro caso". 
Autor delictivo puede ser cualquier persona cuya vinculación con la víctima no agrave el homicidio. Tenemos así que, consistiendo el homicidio en matar a "otro", su autor no puede ser la propia víctima. Ese sería un suicida, y no es punible con arreglo a la mayoría de las legislaciones.

El homicidio encuentra su momento consumativo en el instante de la muerte de la víctima, y admite tentativa. Desde el punto de vista jurídico, una persona está muerta o privada de vida cuando el funcionamiento natural o artificial de su organismo ha cesado. El artículo segundo del Código Civil boliviano, norma en su primer período: "La muerte pone fin a la personalidad.". Corresponde a la ciencia médica decidir cuándo ha sucedido esto, en cada caso concreto.

El homicidio puede someterse mediante actos positivos o conductas negativas. Una conducta negativa responsabiliza por el homicidio si es omisiva, (Comisión por omisión), es decir, si es violatoria del deber de resguardar la seguridad física del sujeto pasivo; es muy conocido el ejemplo de la madre que no cumple su deber de alimentar al hijo. El autor puede utilizar medios materiales o medios morales. Lo esencial es que aquellos o los últimos, causen la muerte de la víctima.

Subjetivamente el homicidio siempre exige el dolo. Este puede ser directo, indirecto o eventual. La voz dolo corresponde a lo que comúnmente llamamos "intención"; los actos antijurídicos pueden someterse con la intención de provocar un mal o, simplemente, con la previsión del resultado dañoso, aunque no mediare intención (DELITO IMPRUDENTE).

VI. HOMICIDIOS CALIFICADOS. 1.ASESINATO. Aunque la mayoría de los códigos modernos usan la nominación genérica de homicidios cualificados, calificados o agravados, para designar los cometidos con causal calificante, el Código Penal Boliviano, en su Art. 252, le llama asesinato, y al igual que el parricidio, o la traición a la patria, tienen por pena treinta años de presidio, sin derecho a indulto, según disposición constitucional $(1967 ; 17)$.

Cuando a la comisión delictiva del homicidio simple concurren determinadas causases de agravación, tenemos la figura del asesinato. Tales condiciones cualificantes del homicidio, pueden catalogarse en:

\section{HOMICIDIO EN RAZÓN DEL VINCULO}

El homicidio se agrava si el autor, sabiéndolo, en el momento del hecho está ligado con la víctima por una relación de parentesco. La doctrina habla del parricidio propio, esto es, la muerte de los padres; de los ascendientes en línea recta, sabiendo que lo son, y el parricidio impropio, que es el que tiene por víctima a los hijos, esposos u otros parientes que no sean los padres. El primero es denominado específicamente parricidio por el Art. 253 de la codificación penal boliviana. Y el segundo, constituye el caso de la primera calificante o agravante en el asesinato, esto es matar: "A sus descendientes, cónyuge o conviviente, la última se justifica por considerarse tal situación como matrimonio de hecho por la normativa constitucional, civil y familiar. 


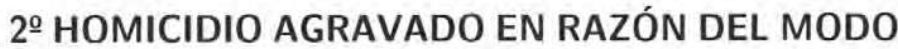

a) Con premeditación, o siendo fútiles o bajos los móviles. La premeditación, supone la deliberada frialdad del asesino que le conduce al delito con la pura reflexión de cómo se ha de ejecutar la acción, la previsión de los detalles, el cuidado observado para asegurar el resultado. Por fútil, se entiende la existencia de poco aprecio por la vida humana. Tanto la premeditación también conocida como dolo determinado, y los medios fútiles, o los bajos móviles constituyen una mayor carga de reprochabilidad en la conducta del agente.

b) Con alevosía o ensañamiento. Alevosía es la cautela que emplea el criminal para cometer un delito con las personas, sin riesgo para que el que actúa a traición, con perfidia y sobreseguro. Es circunstancia del delito, le califica y agrava por la mayor imposibilidad de defensa que su modo de comisión implica. El ensañamiento, es el deleite por causar el mayor daño y dolor posibles, prolongar deliberadamente los padecimientos de la víctima quien ya no está en condiciones de defenderse. Es crueldad innecesaria.

c) Por medio de sustancias venenosas u otras semejantes. En razón de que éstos son administrados insidiosamente, esto es, haciendo tomar o introduciendo la sustancia letal a ocultas de la víctima. Esa es la opinión tradicional.

\section{3ํHOMICIDIO AGRAVADO EN RAZÓN DE LA CAUSA}

a) En virtud de precio, dones o promesas. La muerte de la víctima es querida por el actor, pero ejecutada por un sicario, que recibe pago o recompensa.

b) Para facilitar, consumar u ocultar otro delito, o para asegurar sus resultados. El hecho es considerado asesinato aunque el delito fin no se haya consumado o, habiéndose consumado se quita la vida a la víctima para asegurar sus resultados.

c) Para vencer la resistencia de la víctima o evitar que el delincuente sea detenido. En este tipo penal, es necesaria la comisión de otro delito, mientras que en el caso anterior, existe la cualificante aunque no se haya consumado el delito por el cual se cometió el asesinato. La conexión, en el inciso precedente, es ideológica y subjetiva; en el caso de este inciso, la conexión es causal u objetiva.

\section{4ํHOMICIDIOS ATENUADOS O PRIVILEGIADOS}

Son aquellos en los que el legislador asigna una sanción menos intensa para la acción que la contemplada para la del tipo general o básico, al cual se subordina, por ejemplo: el infanticidio, respecto del homicidio simple. Nuestra codificación penal, considera los siguientes tipos especiales o atenuados. a) Homicidio en Emoción Violenta; b) Homicidio en Prácticas Deportivas; c) Homicidio-Suicidio; d) Homicidio Piadoso -EUTANASIA-; e) Infanticidio; f) El Homicidio Culposo. De estos tipo penales atenuados o privilegiados describiremos, por su importancia, los siguientes:

LA EMOCIÓN VIOLENTA. El caso típico es el del sujeto que encuentra a su esposa acostada con su amante, o a la inversa, menos frecuente. La atenuación se da en razón de que su característica es de shock masivo; se altera por completo el 
equilibrio emocional y mental, de donde resulta una situación casi insoportable. La persona afectada por esta situación de aturdimiento, se siente irresistiblemente arrastrada por un medio inmediato (No necesariamente simultáneo) para aliviar esta tensión. La emoción violenta, tiene sinonimia en los vocablos impulso irresistible o reacción disociativa usados en la terminología psiquiátrica estadounidense. Su duración es pasajera, sin que sea necesariamente inmediata la reacción. No basta que el sujeto haya estado emocionado: la descarga emotiva tiene que coincidir con la ejecución misma del hecho, porque la excusa reside en que por la emoción - no pasión - haya perdido el pleno dominio de sus frenos inhibitorios.

* HOMICIDIO PIADOSO. Conocido también como EUTANASIA. (Art.257). Es bastante polémica su atenuación, porque se discute hasta qué punto una persona no puede disponer de su vida, pero sí la del próximo que pide se la quiten, y evitar así, seguir padeciendo. Para estar privilegiado, el sujeto activo debe estar motivado por un móvil altamente piadoso, y de solidaridad, con aquella persona en estado terminal de su vida por una enfermedad incurable.

* INFANTICIDIO. Comete infanticidio: "la madre que para encubrir su fragilidad o deshonra, diera muerte a su hijo durante el parto o hasta tres días después". Así pues el infanticidio no está configurado por la muerte dada a cualquier infante, sino que es necesario que se ejecute dentro de un plazo determinado, a veces un poco indeterminado como cuando se refiere al período puerperal, que no es uniforme, sino, variable en cada parturienta; que el agente activo sea la madre. Aunque algunos códigos también que el agente activo pueda serlo algún pariente allegado a la madre (padre, hermano, y tal vez algún otro). El infanticidio no es otra cosa que un homicidio castigado con pena menos severa en razón a su móvil.

Entre el INFANTICIDIO y el ABORTO - Legislado en un Capítulo especial - no hay otra diferencia sino que en éste (ABORTO) LO QUE SE DESTRUYE ES LA CRIATURA ENGENDRADA ANTES DE QUE EMPIECE SU ALUMBRAMIENTO, con la desaparición de los derechos que hubieran haber podido corresponder a la persona por nacer: mientras que en aquél, como ya se dijo, se ejecuta después que el parto ha empezado o terminado. 